\title{
A LEITURA DE TEXTOS MULTISSEMIÓticos À LUZ DA GRAMÁTICA DO DESIGN VISUAL
}

\author{
Tulio Lourençoni Maranha \\ Helena Maria Ferreira
}

Submetido em 25 de maio de 2018.

Aceito para publicação em 06 de novembro de 2018.

Cadernos do IL, Porto Alegre, n. ${ }^{\circ}$ 56, novembro. p. 102-117

\section{POLÍTICA DE DIREITO AUTORAL}

Autores que publicam nesta revista concordam com os seguintes termos:

(a) Os autores mantêm os direitos autorais e concedem à revista o direito de primeira publicação, com o trabalho simultaneamente licenciado sob a Creative Commons Attribution License, permitindo o compartilhamento do trabalho com reconhecimento da autoria do trabalho e publicação inicial nesta revista.

(b) Os autores têm autorização para assumir contratos adicionais separadamente, para distribuição não exclusiva da versão do trabalho publicada nesta revista (ex.: publicar em repositório institucional ou como capítulo de livro), com reconhecimento de autoria e publicação inicial nesta revista.

(c) Os autores têm permissão e são estimulados a publicar e distribuir seu trabalho online (ex.: em repositórios institucionais ou na sua página pessoal) a qualquer ponto antes ou durante o processo editorial, já que isso pode gerar alterações produtivas, bem como aumentar o impacto e a citação do trabalho publicado.

(d) Os autores estão conscientes de que a revista não se responsabiliza pela solicitação ou pelo pagamento de direitos autorais referentes às imagens incorporadas ao artigo. A obtenção de autorização para a publicação de imagens, de autoria do próprio autor do artigo ou de terceiros, é de responsabilidade do autor. Por esta razão, para todos os artigos que contenham imagens, o autor deve ter uma autorização do uso da imagem, sem qualquer ônus financeiro para os Cadernos do IL.

\section{POLÍTICA DE ACESSO LIVRE}

Esta revista oferece acesso livre imediato ao seu conteúdo, seguindo o princípio de que disponibilizar gratuitamente o conhecimento científico ao público proporciona sua democratização.

http://seer.ufrgs.br/cadernosdoil/index

Quinta-feira, 22 de novembro de 2018. 


\title{
A LEITURA DE TEXTOS MULTISSEMIÓTICOS À LUZ DA GRAMÁTICA DO DESIGN VISUAL
}

\author{
THE READING OF MULTISSEMIOTIC TEXTS IN \\ LIGHT OF THE GRAMMAR OF VISUAL DESIGN
}

\begin{abstract}
Tulio Lourençoni Maranha ${ }^{1 *}$ Helena Maria Ferreira ${ }^{2 * *}$

RESUMO: O presente trabalho se propõe a analisar as sinalizações indicadas pela Gramática do Design Visual (GDV) para a leitura de textos multissemióticos. Para a consecução do estudo, foi feita uma apresentação de conceitos considerados basilares para a compreensão do processo de leitura de textos multimodais. Além disso, foi realizada uma análise do vídeo "Love on The Brain", com vistas a inventariar elementos não verbais que orientam a produção dos sentidos. Foi possível constatar que são vários os recursos/modos que indiciam sentidos nos textos multissemióticos, razão pela qual tais elementos devem ser considerados pelo leitor na ação leitora e, consequentemente, pelo professor no encaminhamento da prática pedagógica do ensino de língua portuguesa.
\end{abstract}

PALAVRAS-CHAVE: textualidades; gramática do design visual; multissemiose.

ABSTRACT: The present work proposes to analyze the signs indicated by the Grammar of Visual Design $(G V D)$ for the reading of multisemiotic texts. For the accomplishment of the study, concepts considered basic for the understanding of the process of reading multimodal texts were presented. In addition, an analysis of the video "Love on The Brain" was carried out, in order to inventory non-verbal elements that guide the production of meaning. It was possible verify that there are several features/modes that indicate meaning in the multisemiotic texts. For this reason, such elements must be considered by the reader in the reading action and, consequently, by the teacher in the referral of pedagogical practice of Portuguese teaching.

KEYWORDS: textualities, grammar of visual design; multisemiosis.

\section{Introdução}

Nos diversos contextos da atualidade, várias configurações linguísticas/semióticas, textuais e discursivas têm se mesclado no processo de produção de sentidos. Assim, com o advento e com a disseminação das diferentes tecnologias da comunicação e da informação, diferentes formas de linguagem passaram a integrar, de modo exponencial, as produções textuais atuais, em função da facilidade de inserção de diferentes recursos nos processos de textualização dos diferentes gêneros que circulam socialmente. Essas novas formas de composição do texto provocaram um redimensionamento dos textos compostos por elementos alfabéticos, fazendo com que

1* Graduado em Letras pela Universidade Federal de Lavras, tuliolou1 @ hotmail.com

$2^{* *}$ Professora na Universidade Federal de Lavras (Departamento de Estudos da Linguagem e Programa de Pós-Graduação em Educação), doutora pela Pontifícia Universidade Católica de São Paulo, coordenadora de área PIBID/Capes, helenaferreira@del.ufla.br 
coexistam numa mesma produção diferentes modos (fala, escrita, imagens) multimodalidade, com seus diferentes recursos indiciadores de sentido (cores, sons, movimentos, links, imagens, palavras, diagramações, etc.) - a multissemiose.

Nesse contexto, o presente trabalho elege como objeto de discussão a leitura de textos multimodais/multissemióticos, com o propósito de verificar os modos de organização dos elementos constitutivos dos textos e suas interferências no processo de produção dos sentidos. Assim, para sustentar a discussão, toma-se como referência a teoria da Gramática do Design Visual (GDV), proposta por Kress e Van Leeuwen (2006), a qual busca discutir os aspectos presentes na composicionalidade dos textos, em uma perspectiva de três metafunções citadas pelos autores: ideacional, interpessoal e textual.

Para contextualizar a pesquisa, parte-se de uma apresentação dos conceitos de multiletramentos e multimodalidade, com vistas a destacar as peculiaridades dos textos multimodais/multissemióticos. A seguir, busca-se caracterizar, em linhas gerais, a Gramática do Design Visual, com destaque para as três metafunções. Com o intuito de compreender as contribuições da GDV para a leitura de textos multimodais/ multissemióticos, apresenta-se o resultado de uma análise do vídeo "Love on The Brain", com o propósito de inventariar questões que orientam a produção dos sentidos. Esse vídeo explora a temática da beleza como forma de aceitação social. Nesse sentido, os diferentes recursos utilizados pelo produtor favorecem a construção dos personagens e a desconstrução das representações sociais sobre o ideal de beleza.

Desse modo, espera-se que a presente pesquisa possa contribuir, ainda que de modo propedêutico, para uma reflexão sobre a leitura de textos multimodais/multissemióticos, e para a importância de se articular teoria e prática pedagógica para iluminar as discussões sobre o processo de produção de sentidos.

\section{Multiletramentos: em busca da formação do leitor proficiente}

Ao abordar a temática da leitura na contemporaneidade, é essencial que se considere as práticas sociais constitutivas dessa ação humana. Ler não se restringe à decodificação de signos alfabéticos, conforme concebido ao longo dos anos, mas se estende para o processo de interação, por envolver não apenas a materialidade linguístico-textual, o leitor e a comunidade discursiva, como também o modo através do qual os aspectos citados se (re)configuram. A abordagem interativa permite o estudo dos vários elementos que compõem os textos: os gêneros textuais, os suportes, o contexto de produção/recepção/circulação, as relações entre autor-texto-leitor, as questões históricas e ideológicas, entre outras.

Nessa dimensão, faz-se necessário discutir conceitos que emergem dessa concepção de leitura, entre os quais merecem destaque os multiletramentos. Para compreender esse conceito, é relevante reportar à noção de letramento, que segundo Soares (2006, p. 37),

está relacionada a ideia de que - tanto para o grupo social em que a escrita seja introduzida quanto para o indivíduo que aprenda a fazer uso dela - a escrita traz diversas consequências: sociais, culturais, políticas, econômicas, cognitivas, linguísticas. Assim, ao aprender a ler e escrever, ao tornar-se alfabetizado, ao adquirir a "tecnologia" - a habilidade do ler e escrever - e ao envolver-se nas práticas sociais de leitura e escrita, o indivíduo passa a sofrer 
consequências, alterações de diferentes ordens no seu estado ou condição. (SILVA, 2012, p. 26)

A partir do exposto, percebe-se que o letramento se relaciona às interações estabelecidas entre os sujeitos e os textos lidos/produzidos. Desse modo, letramento diz respeito aos usos sociais da linguagem com vistas a atender às demandas interativas das relações cotidianas. Então, o letramento é concebido como uma importante ferramenta no processo de constituição do sujeito como um agente de transformação social.

Nesse sentido, o conceito de letramento é ampliado para além das questões de leitura e de escrita de textos verbais. Para Bagno e Rangel (2005, p. 70), esse conceito vem se mostrando tão produtivo "que seu uso tem sido ampliado para referir-se ao domínio das diversas funções sociais e das habilidades de uma pessoa em outros campos culturalmente estratégicos, além do campo da leitura/escrita de textos propriamente ditos". Nesse contexto, pode-se fazer uma articulação da noção conceitual de letramento com educação linguística. Para os autores, a educação linguística é

\begin{abstract}
conjunto de fatores socioculturais que, durante toda a existência de um indivíduo, lhe possibilitam adquirir, desenvolver e ampliar o conhecimento de/sobre sua língua materna, de/sobre outras línguas, sobre a linguagem de um modo mais geral e sobre todos os demais sistemas semióticos. Desses saberes, evidentemente, também fazem parte as crenças, superstições, representações, mitos e preconceitos que circulam na sociedade em torno da língua/linguagem e que compõem o que se poderia chamar de imaginário linguístico ou, sob outra ótica, de ideologia linguística. Inclui-se também na educação linguística o aprendizado das normas de comportamento linguístico que regem a vida dos diversos grupos sociais, cada vez mais amplos e variados, em que o indivíduo vai ser chamado a se inserir. (BAGNO; RANGEL, 2005, p. 70)
\end{abstract}

Assim, reitera-se a importância de se articular a concepção de letramento ao processo de leitura de textos multimodais/multissemióticos ${ }^{3}$. Se todo o texto se inscreve necessariamente num gênero de texto (ou releva de/em um modelo de gênero), e se os gêneros textuais são produtos culturais, sociais e históricos, os quais existem a partir de determinadas práticas sociais (MARCUSCHI, 2002), não faz sentido dissociar letramento do estudo dos diferentes gêneros textuais.

Direcionando a discussão para os textos multimodais/multissemióticos, Brait (2013) considera que o trabalho com a verbo-visualidade presente nesses textos desempenha um papel importante na leitura da contemporaneidade e no ensino dessa leitura, mas exige empenho e rigor teórico-metodológico. Para a autora,

alguns textos de diferentes gêneros, advindos de diferentes esferas, nos quais a articulação verbo-visual, tecida na instância de produção, funciona, deliberadamente, como projeto de construção de sentidos, de efeitos de sentido, quer lógicos, ideológicos, emocionais, estéticos ou de outra natureza, entretecidos por um diálogo face a face em que alteridades, ao se

3 Vale destacar que os conceitos de multimodalidade e multissemiose, recorrentemente, são utilizados como sinônimos. Para Dionísio (2005), a multimodalidade, que se refere às mais distintas formas e modos de representação utilizados na construção linguística de uma dada mensagem, tais como palavras, imagens, cores, formatos, marcas/ traços tipográficos, disposição da grafia, gestos, padrões de entonação, olhares etc, abrange, portanto, a escrita, a fala e a imagem. Desse modo, salienta-se que a combinação de diferentes semioses geram textos multimodais. 
defrontarem, convocam memórias de sujeitos e de objetos, promovendo novas identidades. (BRAIT, 2013, p. 43)

Nesse contexto, o conceito de letramento se expande para o conceito de multiletramentos, que comporta não apenas os diferentes modos de representação da linguagem presentes nos textos, mas também as dimensões culturais nas quais os textos se inscrevem.

Nessa direção, Lourenço (2013) pontua que

como as práticas de leitura e de escrita são diversas, os letramentos, no plural, também são, visto que dependem do contexto e do objetivo de cada sujeito. $\mathrm{Na}$ sociedade atual, diante das novas tecnologias, existem novos modos de representação da linguagem (verbal, visual, sonora, gestual), novos gêneros textuais, novas formas de ler e de escrever, os quais deram origem ao termo multiletramentos. (LOURENÇO, 2013, p. 1)

$\mathrm{Na}$ busca de compreender essa questão, merece destaque o estudo realizado por Rojo (2009), que considera que os letramentos abarcam vários tipos de letramentos: a) letramentos múltiplos: que consideram os letramentos culturais, na tentativa de articulação das dimensões local/regional e global/planetária, o que permite deixar de "ignorar ou apagar os letramentos das culturas locais de seus agentes (professores, alunos, comunidade escolar) e colocando-os em contato com os letramentos valorizados, universais e institucionais". (ROJO, 2009, p. 107); b) letramentos multissemióticos: que são demandados pelos textos contemporâneos, pois abarcam o campo da imagem, da música, das outras semioses que não somente a escrita. (ROJO, 2009, p. 107) e c) letramentos críticos: que são "requeridos para o trato ético dos discursos em uma sociedade saturada de textos e que não pode lidar com eles de maneira instantânea, amorfa e alienada" (ROJO, 2009, p. 108). Esses tipos de letramentos permitem articular a multissemiose/multimodalidade dos gêneros textuais, as múltiplas práticas de letramentos sociais e a multiculturalidade advinda das diferentes culturas locais.

Discorrendo sobre o processo de leitura desses textos, Silva (2012) exemplifica essa situação a partir da seguinte afirmação:

Se pensarmos em tudo o que envolve uma situação em que se utiliza a língua escrita, como, por exemplo, na leitura cotidiana de um jornal, em que perceberemos que as capacidades envolvidas nesse evento de letramento vão além do que se pode ser ensinado ou aprendido na escola. Desde o momento em que o leitor opta por fazer uma assinatura até o momento em que recebe o jornal em sua casa, ele utilizou diversos saberes sobre relacionamentos comerciais, bancários, etc.; assim como quando olha a primeira página em busca de algo que o interesse, quando faz relações entre as fotos, as legendas e as informações verbais. Esses e outros conhecimentos fazem parte da prática letrada de ler jornal. (SILVA, 2012, p. 27)

Com a noção de multiletramentos, a reflexão sobre sua importância é essencial, uma vez que as novas formas de representação textual presentes no cotidiano social das pessoas se constituem como mecanismos de textualização que conjugam diferentes tipos de letramentos. Lourenço (2013) discorre sobre essa questão, pontuando que, atualmente, o uso da linguagem exige outras habilidades devido ao uso da tecnologia, como saber acessar um site, enviar um e-mail, baixar um vídeo, utilizar redes sociais, editar uma foto, entre outros, de acordo com as necessidades de cada pessoa. Soma-se a 
isso a multiplicidade de linguagens que são conjugadas em uma mesma produção linguística, como imagens estáticas e/ou em movimento, linguagem verbal e não-verbal, sons e animações variadas.

Para elucidar essa caracterização dos textos que circulam na contemporaneidade e que são permeados de diferentes modalidades e semioses, considera-se importante discorrer sobre os conceitos de multimodalidade e multissemiose.

Colocando em evidência o surgimento das novas práticas de letramento e articulando-as aos modos/recursos semióticos, considera-se necessário destacar que os gêneros textuais que circulam socialmente estão sendo transmutados de modo a congregar diferentes elementos indiciadores de sentido. Essa realidade obriga, de certo modo, a uma reconfiguração das relações sociais, já que o acesso às informações se efetiva por meio de diversos artefatos e ferramentas digitais. Para Ferreira e Vieira (2015),

A partir da década de 1980, a sociedade brasileira passou por profundas modificações ocasionadas pela globalização e pela presença das tecnologias de informação e de comunicação. Essas mudanças se deram nas relações sociais, nos modos de veicular as informações e também nos textos que circulam socialmente. (FERREIRA; VIEIRA, 2015, p. 109)

Com todos esses avanços e modificações sociais, a sociedade tem exigido dos cidadãos novos comportamentos e novas formas de interação social. Essas reconfigurações, demandadas pelas mídias transpostas pelo viés tecnológico, trouxeram impactos também nas formas de circulação dos gêneros textuais, que a partir de tais mudanças começam a ganhar novas configurações, tais como acessibilidade a diferentes conteúdos, composição multimodal (fala, escrita, imagens, etc.) e organização multissemiótica (palavras, sons, movimentos, imagens, cores, diagramações, etc.)

Nesse sentido, novas formas de leitura e interpretação são necessárias para lidar com essas novas formas de transcrição dos textos:

Imagem, palavra, cor, gesto e diagramação se complementam, se contrapõem, se integram (ou não), sempre com o propósito de significar mais. Cada uma dessas linguagens pode ser utilizada de modo mais adequado para atingir certo propósito comunicativo e, quando combinadas, o potencial funcional é mais amplo. (FERREIRA; VIEIRA, 2015, p. 112)

É com base nesse novo contexto de produção textual que a multimodalidade vem ganhando seu espaço. A presença de elementos como cores, formas geométricas, sons, hiperlinks, como citado acima, é o que fundamenta o estudo da multimodalidade.

Ainda segundo as autoras supracitadas,

pode-se considerar que o termo "multimodalidade" surge para contemplar a presença desses recursos diversos que constituem os gêneros textuais. A multimodalidade envolve a integração e a conjugação dos sentidos dos textos verbais e não verbais para a construção dos sentidos dos textos. (FERREIRA; VIEIRA, 2015, p. 112)

Esse conceito tem assumido notoriedade no cenário acadêmico-científico a partir da disseminação das tecnologias da informação e da comunicação, que revolucionaram as interações sociais por meio de dispositivos móveis. Assim, a incorporação de práticas de leitura e de produção que contemplem essa diversidade de recursos constitutivos dos 
textos que circulam socialmente é imperiosa. A necessidade que se tem de formar sujeitos leitores com determinados conhecimentos é de grande relevância no âmbito escolar, pois a vida em sociedade demanda por usos públicos da linguagem com suas reconfigurações e ressignificações.

Para melhor entender a multimodalidade, é interessante destacar a posição de Kress e van Leeuwen (2006) a respeito do conceito de "modos", que significa o "conjunto organizado de recursos para a produção de sentido incluindo imagens, olhar, gestos, movimentos, música, fala e efeitos sonoros" (KRESS; VAN LEEUWEN, apud GUALBERTO, 2013, p. 4).

Complementando o exposto, Barton e Lee (2015) consideram que os modos referem-se a "sistemas ou recursos que as pessoas mobilizam na construção de sentido. Eles incluem as linguagens falada e escrita, imagem, som, gesto etc." (BARTON; LEE, 2015, p. 47). Para os autores, os textos multimodais são recorrentes no cotidiano social, especialmente aqueles que convergem em espaços de escrita, em que se podem recriar, postar, compartilhar novas mídias sociais, conjugando o verbal com o visual. Com a propagação dos usos da Internet, tem sido relativamente fácil para qualquer usuário ter acesso ou produzir textos multimodais, em que é possível combinar linguagem, imagens, vídeos, e controlar cor, o layout e a fonte.

Nesse sentido, os ambientes de aprendizagem formal, em que se ampliam as reflexões sobre as práticas de leitura e de escrita, ensejam um investimento em atividades pedagógicas que favoreçam a ampliação dos multiletramentos, a partir da proposição de análises e de produção de textos multimodais/multissemióticos. Para Machado (2014), o ensino de Língua Portuguesa em sala de aula com a multimodalidade se constitui como "um espaço estratégico de transformação social favorecido pelo diálogo e reflexão crítica” (MACHADO, 2014, p. 17). Nessa direção, Menezes, Menezes e Azevedo (2015) pontuam que é papel da escola oportunizar experiências de leitura multissemióticas, para ampliar o repertório linguístico e comunicativo dos educandos.

Desse modo, a multimodalidade tem como interesse os recursos indiciadores do sentido, em diferentes contextos. Os recursos ou modos semióticos são responsáveis por atividades comunicativas representativas de uma determinada comunidade, cujas formas de organização dos modos são provenientes de escolhas sociais, individuais e afetivas dos membros dessa comunidade (cf. LIMA, 2015). Então, como a multimodalidade mostra uma predisposição para a construção de sentido dentro dos diversificados contextos, tem-se justificado a importância do trabalho com textos multimodais.

O ensino da leitura e escrita da linguagem verbal em interação com novas formas de negociação de significado, baseadas na manipulação de diferentes recursos semióticos, como imagens e sons, em uma perspectiva multimodal envolve a percepção de que os padrões de significação são produtos de diferentes contextos e envolvem a manipulação de diferentes modos semióticos.

Para Vieira e Silvestre (2015),

Todos conhecemos o impacto que as imagens têm nos valores, crenças, opiniões e comportamentos dos indivíduos e testemunhamos o crescente domínio deste território como texto. Deste modo, a necessidade de conferir atenção aos significados visuais na sua relação com os significados linguísticos expressos nos textos multimodais são requisitos fundamentais de forma a desenvolver competências críticas de leitura dos textos. (VIEIRA; SILVESTRE, 2015, p. 109) 
As autoras destacam a importância de as escolas investirem na participação dos discursos como forma de emancipação e de fortalecimento dos sujeitos no ato de aprendizagem da cidadania.

Assim, considera-se que a multimodalidade favorece a participação social ao sujeito leitor, uma vez que possibilita o desenvolvimento de modos de leitura em um contexto que é composto por diferentes semioses.

\section{A Gramática do Design Visual}

O presente tópico trará à discussão, foco do presente trabalho, um compilado acerca dos princípios basilares da Gramática do Design visual (GDV), de Krees e Van Leeuwen (2006). Essa teoria foi construída com base na Gramática Sistêmico-Funcional (GSF), proposta por M.A.K. Halliday (1985, 1994, 2004). O contraponto que existe entre as duas teorias é que a GSF tem como objeto de análise as estruturas linguísticas, enquanto que a GDV se apoia na análise de imagens.

A GDV se divide em três metafunções. A metafunção representacional é responsável pelas estruturas que constroem visualmente a "natureza dos eventos, objetos e participantes envolvidos, e as circunstâncias em que ocorrem" (UNSWORTH, 2004, p. 72, apud NOVELLINO, 2003). Essa metafunção utiliza como objeto de análise os elementos constituintes das imagens, que podem ser objetos, lugares, pessoas, em suas respectivas posições. No plano da representação, essa função se relaciona com a construção da experiência, ou seja, a linguagem como uma teoria da realidade, como um recurso para refletir sobre o mundo. A linguagem é usada para representar, falar sobre as experiências no mundo físico e mental, para descrever eventos e estados, para além das entidades neles envolvidos. Os recursos semânticos ideacionais constroem o mundo circundante e o mundo interior (cf. VIEIRA, SILVESTRE, 2015).

As personagens que compõem as imagens possuem também denominações impostas pelos autores: o participante interativo (PI), aquele que observa, produz ou lê a imagem, e o participante representado (PR), aquele que faz parte da composição da imagem. Esse último, por sua vez, pode se subdividir em: i) ator, quando dele partir o vetor e ii) meta, quando o vetor apontar para ele. Vetores podem ser caracterizados como indicativos de ação e linguisticamente são representados pelos "verbos". Nas imagens, os vetores são identificados a partir de linhas visíveis ou imaginárias formadas pelos corpos, ou membros, ou ferramentas em ação, e que indicam processos. Tais processos podem ser caracterizados por dois tipos: narrativo e conceitual.

O tipo narrativo refere-se ao fato de o participante estar conectado por um vetor (fazendo algo para alguém). Esse tipo pode se efetivar por meio de cinco processos:

1) processo de ação: quando os acontecimentos do mundo material são descritos ou apresentados em uma situação em que o participante é o ator, participante de quem o vetor parte, e o alvo, participante que é atingindo pelo vetor. Esse tipo de estrutura corresponde aos processos materiais e comportamentais, no modo verbal, assumindo três configurações: (a) não transacional: a ação não é feita para alguém ou algo (possui apenas um participante, o ator); (b) transacional: a ação é feita para alguém ou algo. Tem-se pelo menos dois participantes, o ator e o alvo; (c) bidirecional: a ação acontece em uma situação em que o participante é ator e alvo da ação, simultaneamente; 
2) processo de reação: quando o vetor é formado pela direção do olhar de um ou mais participantes representados, sendo denominado de reator aquele participante que olha (ser humano, animal, ou qualquer objeto) e de fenômeno aquilo para que ou aquele para quem se está olhando. Nesse caso, pode ser transacional (o olhar do participante dirige-se ao fenômeno que está na imagem) ou não transacional (o olhar é direcionado para algo fora da imagem);

3) processo verbal e mental: são dizeres representados por balões, sendo que o participante é o dizente (do qual emana o balão que indica a fala), e o enunciado é o conteúdo inserido no balão;

4) processo de conversão: envolve uma mudança de status do participante, o retransmissor, que é, simultaneamente, alvo de uma ação e ator de outra;

5) processo de simbolismo geométrico: em que há somente o vetor, indicando direcionalidade, por meio de um sinal de infinito, em vez de uma seta.

Em relação ao tipo conceitual, pode-se identificar três tipos diferentes de processos:

1) Classificacional: em que os participantes se relacionam, exercendo papéis diferenciados de subordinado e subordinante, ou ainda, de participantes intermediários;

2) Analítico: em que os participantes se relacionam em termos de uma estrutura de parte-todo, um deles o portador, o todo, e o outro o atributo, a parte;

3) Simbólico: em que um participante significa ou é, podendo ser atributivo, quando a identidade de um participante (portador) é estabelecida na relação com outro participante (atributo), ou sugestivo, quando o participante representa a própria identidade. (cf. PIMENTA; MAIA, 2014).

A metafunção interativa contempla recursos visuais, que constroem "a natureza das relações de quem vê e o que é visto" (UNSWORTH, 2004. p. 72, apud NOVELLINO, 2003). Nessa metafunção, "a linguagem é concebida como práxis da intersubjetividade", ou seja, a linguagem é vista como recurso para interagir com os outros, para estabelecer e manter relações com as pessoas, influenciar o seu comportamento, expressar o nosso ponto de vista sobre o mundo, provocá-las ou mudálas. De acordo com Kress e van Leeuwen (2006), as representações de interação podem ocorrer por meio dos seguintes mecanismos:

1) olhar: marca uma maior ou menor interação com o leitor, podendo se classificar como demanda - o PR olha diretamente paro leitor (PI) - e oferta - o PR olha para o leitor de maneira indireta;

2) enquadramento/distância entre os participantes interativos e os participantes representados: indicação de proximidade, ou seja, a escolha mais próxima de um ou de outro representa os participantes como mais íntimos de quem os observa, ou como mais distantes ou estranhos, pode representar uma relação imaginária de maior ou menor distância social, que pode ser percebida a partir dos vários tipos de enquadramento: plano fechado (cabeça até ombros); plano médio (cintura para cima); plano aberto (todo o corpo do participante);

3) perspectiva: demonstrada a partir da escolha do ângulo ou ponto de vista a partir do qual os participantes representados são retratados: (a) ângulo frontal: apresenta a imagem no nível do olhar do PI; estabelece o envolvimento entre os participantes, na qual o primeiro é convidado a fazer parte do mundo retratado na imagem; (b) ângulo oblíquo: transmite um sentido de desconexão, apresentando o PR de perfil, revelando que aquilo que se observa não pertence e nem pertence ao mundo do observador; (c) 
ângulo vertical: aponta para as diversas relações de poder que são possíveis de acontecer na composição imagética entre os PR e os PI;

4) modalidade: que se refere à credibilidade das mensagens, ou seja, o conteúdo é verdadeiro, efetivo, real, ou é incoerente ou uma ficção, sendo observada sob quatro dimensões: (a) naturalística: as cores representam o real, indiciando verdades, a ausência de cores (preto e branco) simboliza o irreal, a tonalidade de cores sugere aproximações com a realidade: quanto mais cor, mais real, quanto menos cor, menor é o grau de realidade; (b) abstrata: a verdade visual é a verdade abstrata, expressa na imagem; se as cores apresentarem tonalidade maior ou menor que a realidade concreta, elas passam a expressar sentimentos e emoções; (c) tecnológica: a verdade é baseada em uma utilidade prática da imagem, (d) sensorial: a verdade visual tem por base a consequência de prazer ou desprazer criada pelo visual.

Nessa direção, observa-se que a função discursiva das mensagens é mobilizada no processo de produção ou de leitura das composições imagéticas.

Já a metafunção composicional se refere aos significados obtidos por meio da "distribuição do valor da informação ou ênfase relativa entre os elementos da imagem" (UNSWORTH, 2004, p. 72, apud NOVELLINO, 2003). Essa função está ligada aos modos de organização das mensagens de forma a fazer sentido. Dito de outro modo, a linguagem é vista "como um recurso semiótico da realidade entendida como um processo (discurso) ou como um produto (texto)" (VIEIRA; SILVESTRE, 2015, p. 109). Essa metafunção é responsável pela relação que os elementos constituintes da imagem exercem, assim fazendo que a imagem produza sentido. A metafunção composicional é subdividida em:

1) valor da informação: diz respeito à forma como os elementos constitutivos do texto se relacionam e como participam do processo de construção do sentido. Essa forma de organização pode ser indicada por meio de: (a) dado/novo: em que o dado (direita) mostra elementos já conhecidos e o novo (esquerda) mostra elementos que trazem informações novas ou que se pretende destacar; (b) ideal/real: em que os elementos que ocupam a posição superior na imagem são tomados como ideal, ou seja, aqueles que qual são mostrados como desejados, já a parte inferior da imagem traz elementos literalmente reais que trazem informações mais consistente acerca da imagem superior; (c) centro e margem: a leitura das imagens também pode ocorrer do centro para as laterais, sendo que o elemento central ocupa uma posição de maior importância no texto, já os elementos que são colocados perifericamente na imagem são aqueles que ocupam um segundo plano no sentido que a imagem exerce não tendo tanta relevância quanto o elemento colocado no centro;

2) enquadre: é o elemento utilizado para fazer uma separação entre as imagens. Essa separação é marcada por "linhas divisórias, descontinuidades no uso de cor ou forma, espaços vazios fazem com que os elementos pareçam estar separados, desconectados dos outros elementos composicionais" (NOVELLINO, 2003, p. 88);

3) saliência: evidencia a importância individual de cada elemento na constituição da imagem. Essa saliência é marcada pelo uso de cores mais intensas ou mais suaves, do tamanho maior ou menor de um elemento em relação a outros, uso de contraste entre cores, nitidez, brilho, perspectiva, e elementos que se sobrepõem (NOVELLINO, 2003).

Essas metafunções são detalhadas por Kress e Van Leeuwen (2006), em uma proposta de leitura multimodal, tomando como referência padrões sistematizados a partir da tradição ocidental. 
Como se pode notar, a GDV aborda aspectos relacionados ao estudo das representações, das interações e da composicionalidade dos textos. $\mathrm{O}$ fato de apresentar uma proposta de leitura para construções multissígnicas representa um avanço teórico, pois permite um deslocamento de uma tradição que atribui primazia aos textos verbais e vislumbra possibilidades de realização de leituras menos intuitivas e menos superficiais, embora esteja mais voltada para a leitura de imagens estáticas. A base teórica fornecida pela referida teoria ilumina, substancialmente, a leitura de produções constituídas por imagens em movimento.

\section{Análise do vídeo "Love on The Brain": Ilustrando a Gramática do Design Visual}

Como forma de ilustrar os princípios propostos pela GDV, foi proposta a análise de um vídeo, intitulado "Love On the Brain", que consiste em uma retextualização do vídeo da cantora Rihanna ${ }^{4}$, com a preservação da letra da música.

O vídeo tematiza a questão do ideal de beleza cultuado pela sociedade contemporânea. Para a construção do enredo, os produtores retratam um encontro entre um casal que se conhece por um aplicativo e que renegam, a priori, suas aparências físicas. Nesse sentido, considerando a metafunção interativa, pode-se observar que na condição de participantes interativos, tem-se os produtores das cenas (idealizador, diretor, assistentes de câmeras, de iluminação etc) e os espectadores (público-alvo: usuários de Internet), e na condição de participantes representados encontram-se a moça, o rapaz, vários casais, a atendente do bar, os objetos, o cenário. Os personagens e os objetos são filmados a partir de um objetivo comunicativo, qual seja, ressaltar a questão da idealização da beleza e o rompimento com os padrões sociais. Assim, é possível constatar que as escolhas representam um direcionamento para orientar a compreensão por parte dos leitores do vídeo. As imagens e os movimentos são essenciais para a compreensão do texto e a letra da música ressalta a questão da aceitação social. A cena ilustrada pela imagem de um celular, contendo na tela o aplicativo Tinder - com a indicação de "It's a match!" - apresenta a ideia central que será abordada no texto: um encontro entre um casal.

No entanto, o conteúdo temático e o objetivo comunicativo são explorados a partir de escolhas por parte do produtor, que faz opção por variados recursos não verbais: representação das personagens, das vestimentas, do espaço, dos gestos, dos olhares, dos movimentos de câmera, das perspectivas, dos ângulos. Nesse sentido, merece destaque a forma como a moça é representada ao longo do vídeo. Sugere-se ao leitor deste artigo, a realização de uma pausa na leitura para uma observação mais atenta sobre esse processo de construção.

Conforme pontuado, a linguagem não verbal assume relevância para representar, falar sobre as experiências no mundo físico e mental, para descrever eventos e estados, para além das entidades neles envolvidos. Assim, o vídeo constrói determinadas representações dos personagens (pessoas participantes das cenas) e indicia para uma percepção da assunção de um ponto de vista dos produtores, que buscam ressignificar os padrões de beleza.

4 O vídeo citado pode ser acessado através do endereço virtual https://www.youtube.com/watch?v=z7i5qS5nCAA. 
Considerando os pressupostos teóricos da Gramática do Design Visual (GDV), proposta por Kress e van Leeuwen (2006), a análise de uma produção sígnica por meio das metafunções permite uma visão mais ampliada das potencialidades indiciadoras de sentido sinalizadas pelos diferentes recursos.

No que diz respeito à função representacional, os personagens representados (personagens das cenas) são construídos de modo a evidenciar valores presentes no imaginário social. Para o processo de construção dos personagens, ressalta-se a presença dos tipos de procedimentos: narrativo e conceitual. No tipo narrativo, merecem destaque as cenas que representam a personagem principal se libertando das vestimentas modeladoras. As cenas são destacadas por meio de movimentos do corpo que demonstram a retirada de acessórios, abertura do zíper, retirada de peças que traziam incômodo e, consequentemente, a indicação de liberdade. Esses movimentos/gestos representam um processo denominado processo de ação, de natureza não transacional, em que a personagem pratica uma ação voltada para ela mesma. Essa escolha indicia um direcionamento da atenção do sujeito-leitor para uma problemática relacionada aos padrões de beleza: a aceitação pessoal. Outro processo utilizado para a construção dos sentidos foi o do tipo conceitual, em que se destacam a cena com um casal de idosos, bem como as cenas de moças magras e bonitas que atendem aos padrões de beleza eleitos pela sociedade. Essa construção simbólica, em que se coloca em questão a faixa etária e os ideais de beleza, é ressignificada.

Constata-se que as escolhas das cenas, em seus modos de organização e de movimentos, representam estratégias argumentativas que contribuem para $o$ convencimento do leitor acerca da defesa do ponto de vista de que os ideais de beleza são relativos e que não são garantias de felicidade.

Em relação à metafunção interativa, observa-se uma exploração de diferentes recursos. A questão do olhar, do enquadramento, da perspectiva e da modalidade pode ser verificada em várias cenas. É relevante pontuar que nem sempre a questão da interação entre produtores, personagens representados e leitores-espectadores é contemplada em uma proposta de leitura. Assim, a reflexão sobre os modos como se dão as interações se evidencia de modo substancial para a discussão acerca das discursividades e das textualidades. Entre os recursos, destacam-se: o olhar direto para o espectador e as expressões faciais. Nesse contexto, há uma sinalização para uma busca de interação entre os participantes interativos (sujeito-leitor) e participante representado (moça). Segundo Kress e Van Leeuwen (2006), o olhar do personagem se configura como uma estratégia de construção de uma relação de intimidade com o leitor.

Já a expressão facial desvela uma provocação para uma comoção, para um envolvimento do leitor-espectador com o personagem e, consequentemente, com seus dilemas. Em casos de textos em movimento, as expressões faciais tendem a suprimir descrições utilizadas em textos verbais. No texto em pauta, as expressões faciais evidenciam constrangimento, incômodo, tristeza, comoção, satisfação, entre outros.

Em relação ao enquadramento, observa-se a escolha por diferentes planos, com planos abertos para mostrar o ambiente de modo mais amplo, e com planos fechados, para destacar comportamentos, atitudes e sentimentos dos personagens representados. No que diz respeito à perspectiva, os giros de câmera exploram diferentes formas de retratar os personagens e espaços. No entanto, cabe um destaque para a utilização do ângulo frontal. Os detalhes evidenciam os sentimentos da personagem, provocando, na maioria das vezes, uma mobilização do leitor-espectador. Nesse âmbito, merece atenção o posicionamento da câmera de baixo para cima e da cintura para baixo, nas cenas em 
que a personagem é representada (protagonista principal). Essa escolha feita pelos produtores, além de destacar o movimento, evidencia a ideia de inferioridade por parte da protagonista, a qual, em contrapartida, ao se livrar das vestimentas que lhe apertam, se livra, notadamente, das amarras sociais que ditam padrões de beleza.

No que tange à modalidade, há a presença de cores realísticas, o que conta com a ajuda da iluminação ou a falta dela, com o propósito de construir uma ideia de naturalidade, de aproximação com a realidade não ficcional. Aqui, destaca-se a escolha do vestido de cor vermelha, que, usualmente, está ligado à ideia de sensualidade.

Conforme pontuado anteriormente, uma imagem estática não pode ser lida tomando-se por base os mesmos parâmetros utilizados para uma leitura de uma produção fílmica em que o movimento participa das textualidades. No entanto, considera-se que a leitura de uma imagem em movimento demanda uma segmentação em partes para uma análise mais apurada das questões que lhe são constitutivas. Nesse caso, as teorias que contemplam a leitura de textos imagéticos estáticos podem iluminar a leitura de textos em movimento. Assim, ao se considerar a metafunção composicional, proposta por Kress e Van Leeuwen (2006), tem-se o valor da informação, a saliência e o enquadramento, como recursos que compõem cada quadro de cenas. Nesse sentido, tem-se uma triangulação, que é apresentada em várias partes do vídeo:

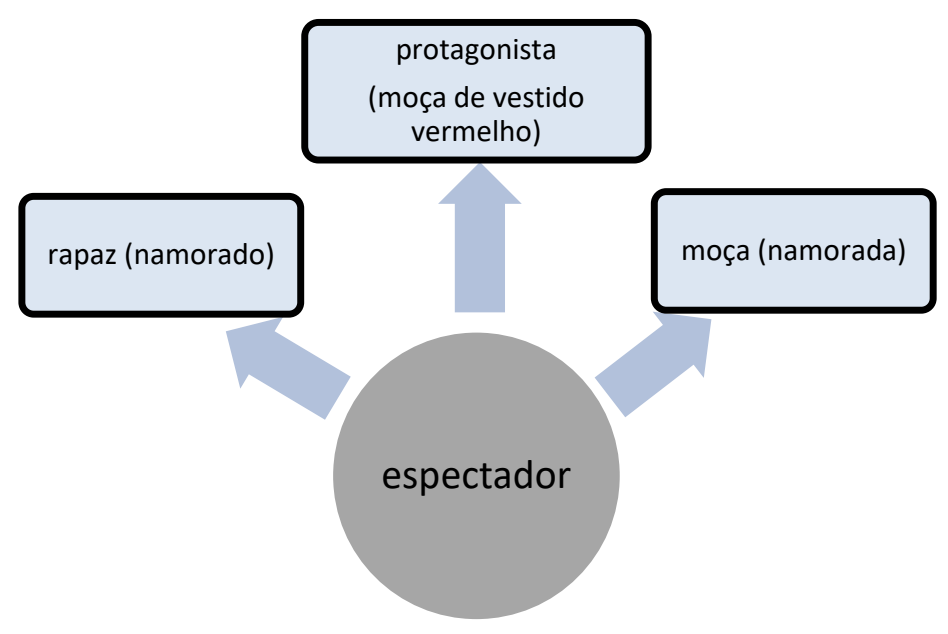

Figura 1: Valor da informação

Fonte: Elaborada pelos autores

Como se observa, a posição dos personagens também é indiciadora de sentidos. $\mathrm{Na}$ apresentação dos personagens, há a ocupação de uma posição. Assim, de acordo com Kress e van Leeuwen (2006), a posição da esquerda se configura como informação já dada ou menos importante, a posição da direita se configura como informação nova ou a ser destacada. No caso da figura um, que representa a cena em que a protagonista é projetada ao fundo, mas entre o casal, parece evidenciar que o contraponto está entre a protagonista e a moça esbelta, já que a temática do vídeo aborda a questão dos ideais de beleza, principalmente, entre as pessoas do sexo feminino. A inserção da personagem principal no centro da imagem chama atenção para o fato de a protagonista não se enquadrar nos padrões de beleza ditados pela sociedade. Embora no texto em movimento essas posições se alterem em função dos giros da câmera, as escolhas de representação parecem não se efetivar de modo aleatório. 
Em relação ao enquadre, percebe-se a presença de alternâncias de personagens ao longo das cenas. Esse movimento com interrupções desvelam descontinuidades, apesar da sequência preservada pela progressão temática. $\mathrm{Na}$ cena em que $\mathrm{o}$ enquadramento aparece pela figura do espelho, a personagem representada é projetada. Isso pode sugerir uma visão de si própria. Como uma pessoa normalmente consegue ver seu rosto e seu corpo (frontalmente), o espelho representa uma percepção de si, que pode ser diferente da visão do mundo exterior. Por fim, a saliência, que é evidenciada por meio de destaques dados aos personagens e aos cenários. Nessa direção, merecem destaque as cores, o tamanho, a focalização. $\mathrm{O}$ vídeo também explora esses recursos. Há cenas em que a personagem representada aparece com nitidez, enquanto os elementos que a circundam figuram de forma desfocada. Chama atenção a cena em que a personagem prende parte da pele para se parecer mais magra, o tamanho da imagem e a perspectiva parecem chamar atenção do leitor para os exageros cometidos em busca da beleza.

Diante do exposto e das análises disponibilizadas, pode-se constatar que os textos multimodais/multissemióticos são constituídos por várias semioses e demandam atenção para a necessidade de uma busca constante de aperfeiçoamento de habilidades de leitura por parte dos leitores, favorecendo a ampliação dos multiletramentos. Nesse sentido, as contribuições trazidas pela GDV podem favorecer o desenvolvimento de uma proposta pedagógica de trabalho com a leitura em sala de aula, na medida em que permitem chamar a atenção para os modos de organização dos recursos semióticos e de suas potencialidades para o processo de produção de sentidos.

\section{Considerações Finais}

O presente trabalho teve por propósito analisar as sinalizações indicadas pela Gramática do Design Visual (GDV) para a leitura de textos multissemióticos. Assim, foram discutidos os conceitos de multiletramentos e multimodalidade/multissemioses. Esses conceitos sinalizam importantes reflexões para o ato de ler, e, consequentemente, para o trabalho com a leitura em sala de aula, em função de se deslocar de uma tradição pautada na leitura de textos verbais para uma perspectiva de gêneros multimodais.

Diante da escassez de estudos que contemplem a leitura de textos multimodais/multissemióticos, a Gramática do Design Visual se constitui como uma teorização que sinaliza para os mecanismos constitutivos dos textos e que contribuem para a produção dos sentidos e para a recuperação das discursividades subjacentes aos textos.

A análise do vídeo "Love on The Brain" possibilitou a percepção dos modos de representação, de interação e de composicionalidade do vídeo, permitindo constatar que as escolhas dos produtores são indicativas de determinados sentidos. Durante a análise do vídeo, o qual busca questionar um padrão de beleza, é possível observar que as escolhas realizadas pelos produtores em relação ao uso dos recursos semióticos encontra-se, intrinsecamente, articulada às formas de representação dos personagens e do conteúdo temático, formas de organização/projeção do cenário e dos personagens, formas de interação com os sujeitos-espectadores e, por consequência, des/re/vela perspectivas que afetam o processo de construção do sentido.

Com este trabalho, foi possível perceber que as teorizações propostas pela GDV podem subsidiar propostas de leitura, levando em consideração recursos semióticos 
como cores, formas, olhares, expressão facial, adereços, movimentos, palavras, perspectivas, enquadramentos e personagens representados.

Nessa direção, depreende-se que a leitura de textos multimodais/ multissemióticos assume relevância pela potencialidade de formar um leitor mais proficiente para a vida em sociedade e para a vida escolar (acadêmica), pois as formas de organização e de circulação dos textos têm sido redimensionadas em uma perspectiva de multimodalidade, o que demanda a formação de sujeitos leitores capazes de lidar com esses textos e de interagir socialmente.

\section{REFERÊNCIAS}

BAGNO, Marcos; RANGEL, Egon. Tarefas da educação linguística no Brasil. Revista Brasileira de Linguística Aplicada, v. 5, p. 63-82. 2005.

BARTON, David; LEE, Carmen. Linguagem online: textos e práticas digitais. Tradução Milton Camargo Mota. São Paulo: Parábola Editorial, 2015.

BRAIT, Beth. Olhar e ler: verbo-visualidade em perspectiva dialógica. Bakhtiniana. São Paulo, v.8, n. 2 p. 43-66, Jul./Dez. 2013. Disponível em: < http://revistas.pucsp.br/index.php/bakhtiniana/article/download/16568/12909>. Acesso 22 ago 2016.

DIONISIO, Angela Paiva. Gêneros Multimodais e Multiletramentos. In: KARWOSKI, Alcir; GAYDCZKA, Beatriz; BRITO, Karim Siebeneicher (orgs). Gêneros Textuais: reflexões e ensino. Rio de Janeiro: Lucerna, 2005.

FERREIRA, Helena Maria; VIEIRA, Mauricéia Silva Paula. Multimodalidade, leitura e escrita: novas práticas de letramento. In: CANO, Márcio Rogério Oliveira. (org). Lingua portuguesa: sujeito, leitura e produção. São Paulo: Blucher, 2015. p. 109 - 124.

GUALBERTO, Clarice Lage. Multiletramentos a partir da gramática do design visual: possibilidades e reflexões. In: Anais do Silel. n. 1. 2013. EDUFU, Uberlândia, 2013.

KRESS, Gunther; VAN LEEUWEN, Theo. Reading images: the gramar of visual design. 5th. London and New York: Routledge, 2006.

LEITE, Josieli Almeida de Oliveira; BOTELHO, Laura Silveira. Letramentos múltiplos: uma nova perspectiva sobre as práticas sociais de leitura e de escrita. Granbery: Revista eletrônica da Faculdade Metodista. Faculdade Metodista, n. 10, 2011. < http://re.granbery.edu.br/artigos/NDMx>. Acesso em: 14 Jan. 2017.

LIMA, Cássia Helena Pereira; PIMENTA, Sonia Maria de Oliveira; AZEVEDO, Adriana Maria Tenuta de. (org) Incursões semióticas: teoria e prática de Gramática Sistêmico-Funcional, Multimodalidade, Semiótica Social e Análise Crítica do Discurso. Rio de Janeiro: Livre Expressão, 2009.

LIMA, Eliete Alves. Multimodalidade e leitura crítica: novas perspectivas para o ensino de língua portuguesa. 2015. 171 f. Dissertação (Mestrado Letras) - Universidade do Rio Grande do Norte, Rio Grande do Norte, 2015.

LOURENÇO, Daiane da Silva. Reflexões sobre contribuições da teoria dos multiletramentos em aulas de língua inglesa e as (im)possibilidades de aplicação no ensino público. 2013. Porto Alegre, 2013.

LOVATO, Cristina dos Santos. Análise das imagens em notícias de popularização científica. Travessias, Letras - UFSM, Santa Maria, Ed. 01. 2010. http://erevista.unioeste.br/index.php/travessias/article/view/4309/3516. Acessado em: 07 mar. 2017. 
MACHADO, Beatriz dos Santos Clemente. A prática de leitura, produção de textos e análise linguística no ensino de língua portuguesa: uma proposta de organização do cotidiano escolar na perspectiva dos multiletramentos. Línguas \& Letras, v. 15, n. 31, fev. 2015. Disponível em: $\quad$ http://erevista.unioeste.br/index.php/linguaseletras/article/view/10893/8193>. Acesso em: 05 nov. 2016.

MARCUSCHI, Luiz Antônio. Gêneros textuais: definição e funcionalidade. In: DIONISIO, Ângela; MACHADO, Anna Rachel; BEZERRA, Maria Auxiliadora (orgs). Gêneros Textuais \& Ensino. Rio de Janeiro: Lucerna, 2002, p. 19-36.

MENEZES, Maria Aparecida Alves; MENEZES, Marylin Vieira de; AZEVEDO, Isabel Cristina Michelan. Hiperconto multimodal como objeto de aprendizagem no ensino de leitura. Interdisciplinar. UFS, v. 22, ano X, jan/jun. 2015. <https://seer.ufs.br/index.php/interdisciplinar/article/view/3831> . Acesso em: 12 mar. 2017.

NOVELliNO, Marcia Olivé. Fotografias em livro didático de inglês como língua estrangeira: análise de suas funções e significados. 2007. 203 f. Dissertação (Mestrado) - Curso de Letras, Pontifícia Universidade Católica do Rio de Janeiro, Rio de Janeiro, 2007. Disponível em: http://www.maxwell.vrac.puc-rio.br/10597/10597_5.PDF. Acesso em: 10 jul. 2015.

PIMENTA, Sonia Maria de Oliveira; MAIA, Denise Giarola. Multimodalidade e letramento: análise da propaganda Carrossel. Desenredo, v. 10, p. 12-20, 2014.

ROJO, Roxane Helena. Letramentos múltiplos, escola e inclusão social. São Paulo: Parábola Editorial, 2009.

ROJO, Roxane Helena; MOURA, Eduardo. Multiletramentos na escola. São Paulo: Parábola, 2012.

SILVA. Cláudia Helena Dutra. Letramento: práticas sociais de leitura e escrita no ensino de línguas adicionais. Via Litterae: v. 4, n. 1, jan/jun. 2012. Disponível em: <http://www.revista.ueg.br/index.php/vialitterae/article/view/5333/3594>. Acesso em: 04 mar 2017.

SOARES, Magda. Letramento: um tema em três gêneros. Belo Horizonte: Autêntica, 2006.

VIEIRA, Josênia; SILVESTRE, Carminda. Introdução à multimodalidade: Contribuições da Gramática Sistêmico-Funcional, Análise de Discurso Crítica, Semiótica Social. Brasília, DF: J. Antunes Vieira, 2015. 